\title{
Psykiatrisk behandling etter barn og unges selvmordsforsøk
}

\author{
Ved Berit Grøholt
}

\begin{abstract}
Alle som gjennom sitt arbeid har regelmessig kontakt med unge mennesker, vil før eller senere stå overfor et ungt menneske som trenger psykiatrisk hjelp etter et selvmordsforsøk. Barne- og ungdomspsykiatrien gir slik hjelp til dem under 18 år, men vi mangler foreløpig en god oversikt over hva som gjøres. Etter min mening trenger vi noen spesifikt tilrettelagte tilnaerminger i Norge, som kan tilpasses den enkeltes bakenforliggende problem. Tiltakene må prøves ut systematisk, for behovet for systematisert kunnskap er stort både nasjonalt og internasjonalt. Her vil jeg skissere erfaringer basert på eget klinisk arbeid og på andres studier. Mer utfyllende beskrivelser kan en finne i bøker og artikler (Brent 1997; Sprague 1997; Hawton 1986; Berman \& Jobes 1991).
\end{abstract}

\section{Evaluering er utgangspunkt for behandling}

Evaluering av fare for gientatt suicidal atferd er første trinn, og er beskrevet i dette nummer av Suicidologi (ses. $5 \mathrm{ff.}$.). 0 ppsummert må vi søke svar på en rekke spørsmål: I hvor stor grad ønsket den unge å dø? H vor farlig var forsøket rent medisinsk? H vilke forhold og problemer utløste selvmordshandlingen? H va ønsket den unge å oppnå? Var det døden, eller å slippe unna en umulig situasjon? $\mathrm{H}$ ar den unge vist suicidal atferd før? $\mathrm{H}$ ar hun/han hatt eller har psykiatriske symptomer eller lidelser? H vilke psykologiske forhold preger den unge? $\mathrm{H}$ åpløsh et over tid? Impul sivitet? Sinne og fiendtlighet? $\mathrm{H}$ vordan har familien det? Er det konflikter, vold, rusmisbruk i familien? Psykiatrisk lidelse? Støtter medlemmene hverandre? $\mathrm{Er}$ det lett tilgang på spesielt farlige selvmordsmidler, som skytevåpen eller farlige medisiner? Ikke noen enkel faktor gir klare holdepunkter, og et ufarlig selvmordsforsøk kan være like alarmerende som et som nesten fører til døden. M en i sum vil svarene gi oss holdepunkter for hvordan hjel pen bør tilrettel egges. I Storbritannia anbefales innleggelse på somatisk avdeling etter et selvmordsforsøk for å gjøre en slik evaluering mulig. En slik hovedregel burde vi også ha i N orge.

\section{Ikke-selvmordskontrakt}

En kontrakt der ungdommen forplikter seg til ikke å skade seg selv i en gitt tidsperiode, er ofte nyttig. Reaksjonen på et slikt kontraktforslag vil i tillegg gi oss informasjon om hvordan den unge og familien ser på og hanskes med situasjonen. I kontrakten må de involverte få vite hvor de kan henvende seg hvis selvmordsimpul ser blir påtrengen de. Jeg foretrekker muntlig kontrakt med skriftlig informasjon om hvem en kan kontakte. M ange undersøkelser har vist at en mulighet for rask kontakt på 24-timers basis forebygger gjentatt selvskade ( $\mathrm{H}$ awton et al. 1998). Kontrakt eller ei: Spørsmålet om selvmordsimpulser hos den unge og foreldres angst for slike bør tas opp med jevne mellomrom gjennom hele behandlingskontakten.

\section{Avbrutt behandling}

Dette er et vanlig problem. Å rsakene kan være mange: Smerten ved å ta inn over seg at et barn ikke fant livet levelig kan være for stor. Behandlingen kan virke uklar og målet uforståelig. Familien føler seg ikke respektert og mangler tillit til behandleren, eller opplever psykiatrisk behandling for stigmatiserende. I familier med mange problemer er risikoen for brudd størst. Følgende forhold kan redusere denne risikoen: Regel messige avtaler tilpasset familiens praktiske virkelighet, ogalltid ny avtale før en skilles. A vgrenset og tids-begrenset behandlingsavtale der fokus for behandling er klart. Familien og ev. andre viktige personer involveres uavhengig av type behandling som blir valgt. Familien og den unge bør kontaktes hvis de uteblir fra en avtale.

\section{Hva slags behandling?}

I barne- og ungdomspsykiatrien i N orge vil som regel hele familien delta i den innledende fasen, der problemer og ressurser kartlegges og en finner fram til tiltak. O fte vil ungdommen få et tilbud om samtalebehandling, mens foreldre møter sjeldnere, og som regel med en annen behandler. A ndre ganger møter hele familien sammen til familieterapi (G røholt 1999). Vi har foreløpig ingen norske studier som sier noe om hva som hjelper, og for hvem. Derfor må vi hente systematisk erfaring fra utlandet. Det kan virke overraskende at vi også internasjonalt har få studier å holde oss til. Her vil jeg nøye meg med å beskrive noen fellestrekk fra studiene.

\section{Hjelp til den unge}

A ngst og depresjon er meget vanlige problemer for suicidal ungdom, og tiltak rettes ofte mot disse tilstan dene. Fokuserte og tidsavgrensede tilnærminger har på kort sikt vist best effekt, og foretrekkes av de unge (Brent et al. 1997). Best studert er to behandlingsformer som kalle kognitiv atferdsterapi og interpersonlig terapi. I N orge er mange opptatt av å tilegne seg en av disse to metodene. Prinsipper $\mathrm{i}$ metodene er nyttige også utenfor terapien.

U tgangspunktet er den innledende evalueringen. De problemer som utløste selvmordsatferden, vil være viktige for hva en velger å sette søkelys på. Den unges ønske om forandring er drivkraften i behandlingen, og forandringsønsket er ofte knyttet til den konflikten eller skuffelsen som ledet til sel vmordsforsøket. Her vil jeg føye til en viktig erfaring fra Finland: Der ingen utløsende årsak finnes, er risikoen for senere selvmord særlig stor. Det kan henge sammen med en vedvarende indre følelse av håpløshet, eller med at symptomer på en mer alvorlig psykiatrisk lidelse ikke registreres. Vi vet at både

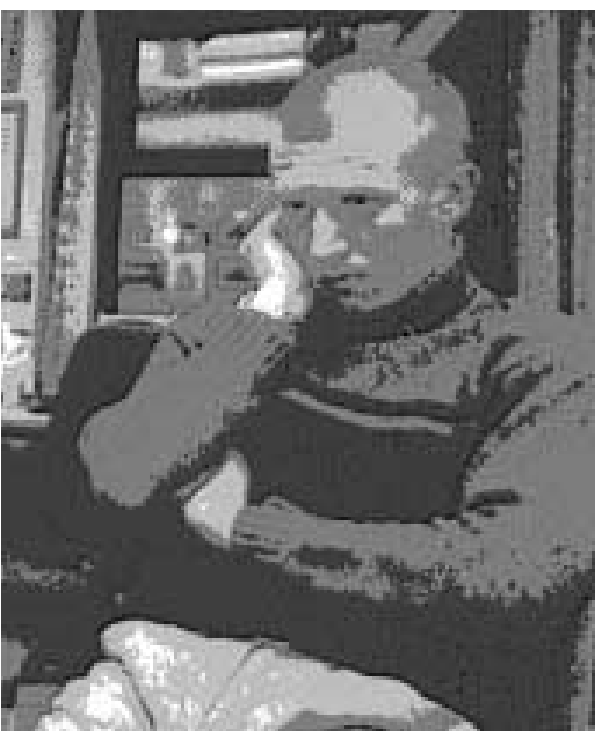


schizofreni og bipolare lidelser (psykoser) ofte starter $\mathrm{i}$ tenårene, og at det går lang tid fra symptomene debuterer til diagnosen stilles. I denne perioden med ensomhet og forvirring for den unge er risikoen for selvmord øket.

Selv om slike prosesser overses for ofte, er allikevel depresjon, angst og atferdsforstyrrelser langt vanligere, og de utløsende årsakene til selvskaden er oftest knyttet til forholdet til andre mennesker. I korttidsterapiene kan en gå gjennom konkrete episoder der den unge, som jeg vil omtale som "hun", har følt problemer i forhold til andre. I mange tilfelle vil hun ha feiltolket situasjonen og følt seg avvist uten reell grunn. Da blir oppgaven i terapien å oppmuntre henne til å prøve ut en annen tolkning: "De i klassen overser meg ikke fordi jeg er så dum og stygg." Kanskje henger det sammen med at hun ikke hilser og ser ned hver gang hun kommer inn $\mathrm{i}$ klassen. $\mathrm{N}$ år hun prøver seg på et hei og et smil og hun registrerer at reaksjonen fra andre endrer seg, har hun tatt et første skritt for å rydde unna selvnedvurderende feiltolkninger. A ndre ganger vil målet være å trene seg opp i "sosial e ferdigheter". M idlene kan være rollespill i timene, eller øvel ser i trygge omgivelser (f. eks. å si terapeuten sin hjertens mening), som gradvis overføres til miljøet der konfliktene oppstår.

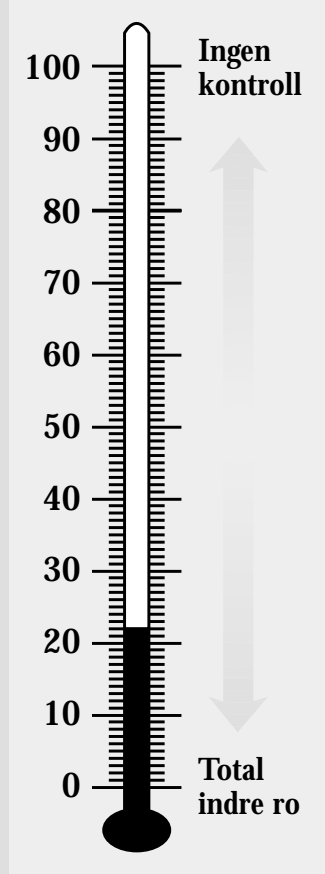

Evnen til å kontrollere sine egne følelser er viktig for å gjøre en krangel konstruktiv, og kan trenes opp. En terapeut ( $R$ otheram-Borus et al. 1994) har innført et "følelsestermometer". $\mathrm{H}$ un og den unge graderer følelsene i ulike situasjoner fra 0 (total indre ro) til 100 (ingen kontroll). Den unge kan lære å unngå situasjoner som bringer henne ut av kontroll. I andre situasjoner trener hun på å kjenne igjen tegnene på følelsesstorm, og øver seg på å bakke tilbake til den "temperaturen" der hun fortsatt tenker rasjonelt. Får den unge opplevelsen av å påvirke omgivelsene sine, er det et skritt i riktig retning.

Er selvmordsforsøket utløst av at en kjæreste har trukket seg, er selvfølelsen i fokus. O pplevelsen av at ens verdi som menneske avhenger av én enkelt persons reaksjon, er en vanlig feiloppfatning som kan bearbeides. Kognitiv atferdsterapi tar utgangspunkt i mistolkninger og selvnedvurdering som melder seg automatisk, mens interpersonlig terapi fokuserer direkte på et vanskelig forhold til en viktig person, uavhengig av hva som er årsak til depresjon. Begge behandlingene kan kombineres med medikamentell behandling hvis de ikke har vist effekt etter noen måneder. Indikasjonene for medisinering vil ikke bli beskrevet nærmere her.

\section{Hjelp til familien}

I familieterapi er målet for behandlingen å modifisere kommunikasjon mellom medlemmene, eller endre fastlåste oppfatninger eller forklaringer (narrativer) som er felles for familien. Er ungdommene utagerende og/eller involvert i rusmiddelmisbruk og antisosial atferd, er metodene over sjel den tilstrekkelige. Best effekt finner en ved meget omfattende tiltak rettet mot den unge, mot hele familien og den unges miljø, som i multisystemisk terapi (H enggeler er al. 1999).

\section{Psykoedukasjon}

G od erfaring har en med å gi familien kunnskap om selvmordsatferd. M ange foreldre tror at barnet deres gjør seg til og manipulerer når de beskriver sine vansker, og kunnskap vil gi dem en bedre forståelse av barna sine.

$M$ ange av de problemene og lidel sen som fører til selvmordsforsøk har en tendens til å komme tilbake, som f. eks. depresjon eller skuffelser i kjærlighetsforhold. A lære den unge og familien å kjenne igjen tegn på at det bygger seg opp mot en selvmordskrise, er en viktig del av kunnskapsformidlingen. De trenger informasjon om hvor de i så fall igjen kan skaffe hjelp. Et viktig mål for hjel peapparatet og politikere er å sørge for at slike tilbud eksisterer.

\section{Varighet av hjelpetilbudet}

$M$ ange av tilbudene nevnt over er kortvarige og avsluttes etter noen måneder. Selv om det har mange fordeler $i$ utgangspunktet, mener jeg at det sjelden er tilstrekkelig. Vi burde også samle erfaring med det som kalles "booster sessions", det vil si sjeldnere oppfølgingssamtaler over tid for å se hvordan det går.

\section{Psykodynamisk psykoterapi}

Psykoterapi slik det praktiseres de fleste steder i N orge i dag går over lang tid, og målet er å arbeide med de helt spesielle opplevelser den enkelte har bak seg som har bidratt til at hun er den hun er. $\mathrm{N}$ år unge velger å forplikte seg i en slik terapi, oppleves det meningsfullt både for terapeut og behandler. Dette bør fortsatt være et tilbud, men flertallet unge og familier vil nok foretrekke de mer avgrensede tilnærmingene som vi må utvikle bedre i årene som kommer.

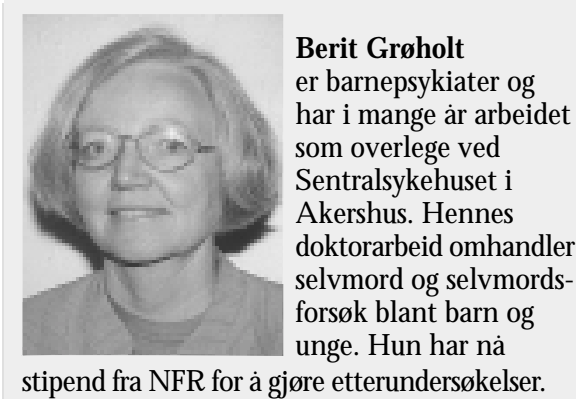

\section{Referanser}

Berman A . L., Jobes D. A . A dolescent suicide: A ssessment and intervention. W ashington $D C$ : A merican Psychological A ssociation, 1991

Brent D. A . T he aftercare of adolescents with deliberate self-harm. Journal of C hild Psychology and Psychiatry 1997; 38: 277-86.

Brent D. A ., H older D., Kolko D., Birmaher B. Baugher M., R oth C., lyengar S., Johnson B. A . A clinical psychotherapy trial for adolescent depression comparing cognitive, family, and supportive therapy. A rchives of G eneral Psychiatry 1997; 54: 877-85.

G røholt B. Familieterapi, systemteori og selvmordsatferd. Suicidologi 1999; 4: 10-2.

$\mathrm{H}$ awton $\mathrm{K}$. Suicide and attempted suicide among children and adolescents. London: Sage, 1986.

$H$ awton $K$, A rensman $E$, Townsend $E$, Bremner $S$, Feldman E, G oldney R, G unnell D, H azell P, van $H$ eeringen $K, H$ ouse $A, O$ wens $D$, Sakinofsky I, Traskman-Bendz. D eliberate self harm: 
Forts. fra forrige s.

systematic review of efficacy of psychosocial and pharmacological treatments in preventing repetition. British Medical Journal 1998; 317: 441-447

H enggeler S. W., Rowland M. D., Randall J., Ward D. M., Pickrel S. G., C unningham P. B., M iller S. L., Edwards J., Zeal berg J. J., H and L. D., Santos A. B. Home-based multisystemic therapy as an alternative to the hospitalization of youths in psychiatric crisis: clinical outcomes. Journal of the $A$ merican $A$ cademy of $C$ hild and $A$ dolescent Psychiatry 1999; 38: 1331-9.

Rotheram-Borus M. J., Piacentini J., M iller S., G raae F., Castro-Blanco D. Brief cognitivebehavioral treatment for adolescent suicide attempters and their families. Journal of the A merican A cademy of $\mathrm{C}$ hild and $\mathrm{A}$ dol escent Psychiatry 1994; 33: 508-17.

Sprague T. Clinical management of suicidal behaviour in children and adolescents. C linical Child Psychology and Psychiatry 1997; 2: 113-23.

Forts. fra s. 10

\section{Referanser}

Berntsen G, H usby R: Behandling av selvmordsfors $\phi$ kere $i$ somatisk avdeling Tidsskr. N or. Lægeforen. 1994; 114: 2374-2378

Burmo M, Borg SE, Dieserud G, Sveum BD: Selvmordsfors $\phi k$ i Bærum 1984-1988. Rapport om det oppf $\phi$ lgende arbeid etter selvmordsfors $\phi \mathrm{k}$ i Bærum kommune. Bærum kommune, Helseetaten 1990

Dieserud G, M athiesen KS, Dal gard OS: Veileder: selvmordsforebyggende arbeid: Bærumsmodellen. O slo: Senter for sosialt nettverk og helse, 1993

Dunne DJ: Following a suicide postvention. I: Bongar B: Suicide, guidelines for assessment, management and treatment. $\mathrm{N}$ ew York: Oxford U niversity Press, 1992

Forskrift om $\phi$ yeblikkelig hjelp i det psykiske helsevernet. FO R 2000-12-21 nr 1409

Forskrift om etablering av tvungen psykisk helsevern mv. FO R 2000-12-21 nr 1410

Lingjærde 0 : Medikamentell behandling i oppf $\phi$ lging etter selvmordsfors $\phi k$. Suicidologi 2001 $6(2): 14-16$

Lov 1999-07-02 nr 62: Lov om etablering og gjennomf $\phi$ ring av psykisk helsevern (psykisk helsevernloven)

M ork E, Ekeid G, Y stgaard M, M ehlum L, H olte A : Psykososial oppfølging etter parasuicid ved medisinske sykehusavdelinger i Norge. Tidsskr. N or. Lægeforen. 2001; 121: 1038-43

Prosjektplan og handlingsplan mot selvmord 1994-1998. Skriftserie 4-95. O slo: Statens helsetilsyn, 1995

Retterstøl N : Samarbeid og svikt innen behandlingssystemet. Suicidologi 1999; 41: 18-20

Tiltak mot selvmord: oppf $\varnothing$ lgingsprosjekt: prosjektplan utarbeidet av Statens helsetilsyn. O slo 2000. U tgitt som suppl. til Suicidologi 2000.

\section{Forts. fra s. 7}

\section{Referanser}

M ayfield D, M CLeod G, Hall P. The CAGE questionnaire: validation of a new alcoholism screening instrument. A m J Psychiatry 1974; 131:1121-1123.

M ontgomery SA, A sberg M. A new depression scale designed to be sensitive to change. Brit J Psychiatry 1979; 134:322-89.

\section{Aktuell litteratur på området}

Bruland V råle G: M $\phi$ te med det selvmordstruede menneske. O slo: A d N otam G yldendal, 2000.

Chiles JA, StrohsahI KD. The Suicidal Patient. Principles of Assessment, Treatment, and Case Management. W ashington DC: A merican Psychiatric Press, 1995.

M ehlum L (red): Tilbake til livet. Selvmordsforebygging i teori og praksis. Kristiansand: H øyskoleforl aget, 1999.

Retterstøl, N : Selvmord. O slo: U niversitetsforlaget, 1995.

\section{Forts. fra s. 18}

Rønnestad M H. Psykoterapiforskning: Noen utviklingslinjer og betraktninger om "the Dodo bird verdict": "Everybody has won and all must have prizes." Tidsskrift for N orsk Psykologforening 2000; 37: 1003-1016.

Shneidman, ES. Suicide as psychache: a clinica approach to self-destructive behavior. $\mathrm{N}$ ortvale, N J: A ronson, 1993.

Shneidman, ES. Suicidology and the university: a founder's reflections at 80 . Suicide and LifeThreatening Behavior 2001; 31 (1): 1-8.

van der Sande R, Buskens E, A llart E, van der $G$ raaf $Y$, ven Engeland $H$. Psychosocial intervention following suicide attempt: a systematic review of treatment interventions. A cta Psychiatr Scand 1997; 96: 43-50.

W eishaar ME, Beck AT. Cognitive approaches to understanding and treating suicidal behavior. I: Blumenthal S], Kupfer DJ, red. Suicide over the life cycle: Risk factors, assessment, and treatment of suicidal patients (pp. 469-498). W ashington, DC : A merican Psychiatric Press, 1990

\section{Ny norsk doktoravhandling:}

\section{Tyssen, Reidar}

Mental health problems among medical students and young physicians: a nationwide and longitudinal study.

U niv. i O slo, Institutt for medisinske atferdsfag, 2001
Vråle, Gry Bruland

\section{Møte med det selvmordstruede mennesket.}

2.utgave.

Oslo: Gyldendal Ad Notam, 2000. 150 sider.

Dette er en revidert utgave av boken med samme tittel som utkom første gang i 1993. M ye har skjedd i sektoren siden førsteutgivelsen og en revisjon var etterlengtet. Innholdsmessig presenteres fagstoffet med en god balanse mellom fremstilling av teoretisk viten omkring selvdestruktiv atferd og praktisk anvendelig kunnskap.

Innholdet er konkret og klinisk rettet med f.eks. omtaler av konflikter som kan oppstå i behandling av selvmordsnære mennesker. $\mathrm{N}$ år temaet blir så konkret som her, kan fremstillingen fort bli som i en prosedyrebok. Det har forfatteren klart å unngå. Teksten gir anvisninger, men samtidig rom for egen vurdering. Boken fremstår som kompetent og dekken de i forhold til hva den tar mål av seg til å presentere, og med det nødvendige optimistiske grunnsyn. Det kommer tydelig fram at faglig og personlig innsikt er en forutsetning $i$ arbeidet.

Boken henvender seg i første rekke til sykepleiere som møter selvmordsatferd i sitt arbeid, og til studenter $i$ grunn- og videreutdanning i sykepleie. M an kan diskutere hvorvidt det er god prioritering å utgi en bok som ekspl isitt henven der seg til sykepleiegruppen når temaet er et fagområde (suicidologi) som i sin natur er slik at ingen faggrupper kan sieså ha monopol på yte omsorg og behandling, og hvor de praktiske handlinger ofte ligger i det tverrfaglige landskap. $\mathrm{N}$ år det pekes på dette forholdet, er det fordi boken kan fylle et behov for lærebøker langt utover sykepleiefagets rekker.

Dag W illy Tallaksen 